\title{
STUDY ON THE EFFECTIVENESS OF YOGA AS A CONTROL MEASURE FOR BRONCHIAL ASTHMA
}

\author{
Mini K1, M. N. Vasudevan ${ }^{2}$
}

${ }^{1}$ Additional Professor, Department of Physiology, Government Medical College, Manjeri,

${ }^{2}$ Assistant Director, RAIC, Kunnamkulam.

\begin{abstract}
BACKGROUND
ABSTRACT

The interest of Western Medical Scientists in the study and on hatha yoga techniques (Uddiyana and Nauli) was started by Swami Kuvalayananda. Around 1920 and 1924, he established Kaivalyadhama, an institution totally devoted to yogic research training and treatment at Lonavla near Bombay. A study by Nagarathna and Nagendra concerned with yoga for bronchial asthma shows a reduction in the number of attacks per week, severity score, drug treatment score and an improvement in peak flow rate. In a study of autonomic responses to breath holding and its variations following pranayama, there was significant increase in breath holding time. In a study of the effect of yoga breathing exercises on airway reactivity in subjects with asthma, mean forced expiratory volume in $1 \mathrm{sec}$ (FEV1), PEFR, symptom score and inhaler use improved in yoga group compared to placebo, but the differences were not significant. So a study comparing the effect of selected Yoga methods before and after yoga training is relevant.
\end{abstract}

\section{MATERIALS AND METHODS}

This is an uncontrolled clinical trial. The patients with history of asthma were selected from the Yoga group of Sathyananda Yoga Centre and they were given a package of selected Yoga training. In this study, the effectiveness of yoga as a control measure for asthma is studied by comparing the effect of Yoga training on the following parameters.

1. Respiratory rate.

2. Chest expansion.

3. Body mass index.

4. Breath holding time.

5. Pulmonary function tests.

In addition, a questionnaire was given to the 25 asthma patients about the frequency and severity of symptoms before and after yoga.

\section{RESULTS}

Respiratory rate was in the range of $16 / \mathrm{min}-34 / \mathrm{min}$ before yoga and it reduced to $14 / \mathrm{min}-30 / \mathrm{min}$ after yoga in this group. Mean reduction in respiratory rate is highly significant. The chest expansion was in the range of $5 \mathrm{~cm}-9 \mathrm{~cm}$ before yoga and $5 \mathrm{~cm}-$ $11 \mathrm{~cm}$ after yoga in asthmatics. The increase in chest expansion is highly significant. The study shows a highly significant change in breath holding time after yoga. BHT was noticed to be in the range of $10 \mathrm{sec}-45 \mathrm{sec}$ before yoga and it increased to the range of 15 sec - $50 \mathrm{sec}$ after yoga. So, the change is highly significant. BMI was in the range of $15.5 \mathrm{~kg} / \mathrm{m} 2-30.7 \mathrm{~kg} / \mathrm{m} 2$ before yoga and 15.5 $\mathrm{kg} / \mathrm{m} 2-29.7 \mathrm{~kg} / \mathrm{m} 2$ after yoga. The reduction in BMI is highly significant. All the pulmonary function parameters including ERV, IC and PEFR showed a significant increase in asthmatics, whereas in normal subjects only vital capacity, forced vital capacity, FEV1 and MVV were increased significantly. This shows that the effect of yoga is more profound in asthmatics than in normals as far as PFT is concerned. A subjective decrease in frequency and severity of symptoms was observed in most of the asthmatics following Yoga.

\section{CONCLUSION}

The practice of specific yoga postures can produce significant reduction in respiratory rate, body mass index and a significant increase in chest expansion and breath holding time. Moreover, all the pulmonary function tests showed a significant improvement after Yoga training. A profound effect on respiratory system can be produced by practice of specific Yoga postures and a subjective decrease in the frequency and severity of symptoms can be produced in bronchial asthma. The daily practice of yoga can be used as a control measure for bronchial asthma.

\section{KEYWORDS}

Pulmonary Function Tests, Chest Expansion, Breath Holding Time.

HOW TO CITE THIS ARTICLE: Mini K, Vasudevan MN. Study on the effectiveness of yoga as a control measure for bronchial asthma. J. Evolution Med. Dent. Sci. 2017;6(95):7044-7050, DOI: 10.14260/jemds/2017/1528

'Financial or Other Competing Interest': None.

Submission 21-10-2017, Peer Review 07-12-2017,

Acceptance 14-12-2017, Published 23-12-2017.

Corresponding Author:

Dr. Mini K,

Additional Professor

Government Medical College, Manjeri.

E-mail:melminivasudevan@gmail.com

DOI: $10.14260 /$ jemds/2017/1528

(c) (i) $(9)$

\section{BACKGROUND}

The interest of Western Medical Scientists in the study and on hatha yoga techniques (Uddiyana and Nauli) was started by Swami Kuvalayananda. Around 1920 and 1924 he established Kaivalyadhama, an institution totally devoted to yogic research training and treatment at Lonavla near Bombay. A study by Nagarathna and Nagendra concerned with yoga for bronchial asthma shows a reduction in the number of attacks per week, severity score, drug treatment score and an improvement in peak flow rate. In a study of autonomic 
responses to breath holding and its variations following pranayama, there was significant increase in breath holding time. In a study of the effect of yoga breathing exercises on airway reactivity in subjects with asthma,[1] mean forced expiratory volume in 1 sec (FEV1), PEFR, symptom score and inhaler use improved in yoga group compared to placebo, but the differences were not significant. So a study comparing the effect of selected Yoga methods before and after yoga training is relevant.

\section{MATERIALS AND METHODS}

This is an uncontrolled clinical trial. The study is conducted by taking the following parameters before and after a course of Yoga training done under guidance of Sathyananda yoga centre in Calicut.

\section{Exclusion Criteria}

1. Subjects without history of bronchial asthma.

2. Subjects following any other lifestyle modifications other than yoga.

3. Tuberculosis, diabetes mellitus, history of smoking, other serious ailments.

\section{Inclusion Criteria}

The patients with history of bronchial asthma doing Yoga in Sathyananda Yoga Research Centre were included for the study.

The parameters measured were respiratory rate, chest expansion, body mass index, breath holding time, and pulmonary function tests, namely Vital capacity, ERV, Inspiratory capacity, FVC, FEV1, FEV1/FVC, PEFR and MVV.

In addition, a questionnaire was given to 40 asthma patients about the frequency and severity of the symptoms before and after yoga.

\section{Study Design}

Uncontrolled clinical trial.

\section{Sample Size and Sampling Technique}

Sample size is taken as 40 as per convenience. All persons with history of bronchial asthma doing Yoga practice in Sathyananda Yoga Research Centre regularly were included for the study.

\section{Statistical Methods}

Paired ' $t$ ' test was done to compare the different parameters after practicing Yoga daily for 1 hour for a period of 40 days in asthmatics.

Standard deviation and standard error were calculated for the difference in each parameter after yoga practice. From the ' $t$ ' value obtained, the significance of difference in each parameter was calculated using paired test. The yoga postures for training the bronchial asthma patients were selected after discussion with the yogacharya.

\section{The Yoga Postures were-}

1. Bhujangasana.

2. Dhanurasana.

3. Vakrasana.

4. Ushtrasana.

5. Sarvangasana.

6. Surya Namaskara.
7. Mathsyasana.

8. Padahastasana.

9. Bhasthrika.

10. Poornaswasanakriya.

11. Yoganidra.

12. Jalanethi.

13. Suthranethi.

14. Vastradhauthy.

\section{Selection of Patients}

Detailed history of subjects doing Yoga training in the Sathyananda Yoga Centre, Calicut was taken and those with history of bronchial asthma are selected for the study. A questionnaire was given to the 40 asthma patients about the frequency and severity of symptoms before and after yoga practice. Respiratory rate noted and chest expansion measured using a measuring tape. The weight of the subjects were taken in kilograms and height in centimetre and converted into metres. Body mass index was calculated by the-

\section{Formula. $\mathrm{BMI}=\underline{\text { Weight } \text { in } \mathrm{Kg}}$ Height in $\mathrm{m} 2$}

\section{Pulmonary Function Tests/ Selection of Equipment}

Equipment selection is done and the instrument used was a portable small computerised spirometer from Jaeger named "Flow screen." A pneumotach is attached to the handle. An elbow piece extension is connected to the side of the pneumotach, to which the mouth piece is attached. The pneumotach registers the measuring values, which is displayed by computer system on the screen.

\section{Procedure}

Biodata was collected from the subject. Age was confirmed by obtaining the date of birth. No subject was tested at the time when he or she had an upper respiratory infection. All tests were done at the same time of day to avoid possible diurnal variations.

Physical parameters were then recorded. Standing height in $\mathrm{cm}$ and weight in kilograms. The pneumotach is calibrated once a day using the calibration pump provided. All tests were performed in the sitting position. After subject was comfortably seated, he or she was instructed to loosen any tight clothing. The procedure was explained in simple terms. Before the beginning of each test, the appropriate technique demonstrated. A disposable mouth piece was used for each subject. The mouth piece was positioned, so that the subject's chin was slightly elevated and neck extended. After the insertion of mouth piece, a check was made to ensure that no leaks were present. The subject was exhorted to make a maximal effort for each test and was closely watched to ensure that he or she maintained an airtight seal between the lips and mouthpiece of the instrument.

\section{Spirometry}

First the subject's data were entered, i.e. ID No., Name, Date of Birth, Sex, Height and Weight. Then the required measurement was called up from the menu. We first do the spirometry (F1) for finding out vital capacity, expiratory reserve volume and inspiratory capacity. The subject was 
seated comfortably with the nose clip in place. The subject was then asked to breathe via the mouth piece attached to the pneumotach. At first, he was asked to breathe slowly. This ensures that the subject is in a state of rest and establishes the resting end expiratory level. This level serves as a point of reference for the subsequent measurements. Then the subject was urged to inspire fully and then after reaching a plateau at maximum inspiration to expire maximally. The expiration was performed as deeply as possible, but slowly. Three consecutive determinations were done and VC, ERV and IC recorded from the best of the 3 tests.

\section{Flowmetry}

The measurement flow/ volume (F3) is called up from the menu. Posture of the subject is same as that of the previous test. The subject was asked to completely exhale and then inhale deeply as possible, then breathe out as rapidly forcefully and completely as possible. If the expiration is less than 1 second the procedure should be repeated to find out the results, the end key is pressed and the parameters, VC, FVC, FEV1, FEV1/ FVC and PEFR are recorded from the screen. The reference predicted values are obtained with the percentage of predicted value from the screen.

\section{Measurement of MVV}

To measure MVV. The subject was instructed to breathe deeply and rapidly as possible, the maximal possible amount of air over a $12 \mathrm{sec}$ interval, after applying the no sec lip. After $12 \mathrm{sec}$ the program is ended automatically and the parameter is extrapolated to 1 minute and shown on the screen with the actual/ predicted value comparison.

\section{RESULTS}

Respiratory rate was in the range of $16 / \mathrm{min}$ - 34/ min before yoga and it reduced to $14 / \mathrm{min}-30 / \mathrm{min}$ after yoga in this group. Mean reduction in respiratory rate is highly significant. The chest expansion was in the range of $5 \mathrm{~cm}-9 \mathrm{~cm}$ before yoga and $5 \mathrm{~cm}-11 \mathrm{~cm}$ after yoga in asthmatics. The increase in chest expansion is highly significant. The study shows a highly significant change in breath holding time after yoga. BHT was noticed to be in the range of $10 \mathrm{sec}-45 \mathrm{sec}$ before yoga and it increased to the range of $15 \mathrm{sec}-50 \mathrm{sec}$ after yoga. So the change is highly significant.

BMI was in the range of $15.5 \mathrm{~kg} / \mathrm{m} 2-30.7 \mathrm{~kg} / \mathrm{m} 2$ before yoga and $15.5 \mathrm{~kg} / \mathrm{m} 2-29.7 \mathrm{~kg} / \mathrm{m} 2$ after yoga. The reduction in BMI is highly significant. All the pulmonary function parameters including ERV, IC and PEFR showed a significant increase in asthmatics, whereas in normal subjects only vital capacity, forced vital capacity, FEV1 and MVV were increased significantly. This shows that the effect of yoga is more profound in asthmatics than in normals as far as PFT is concerned. A subjective decrease in frequency and severity of symptoms was observed in most of the asthmatics following Yoga. The difference observed in BMI, RR, Chest Expansion and BHT after yoga practice and its significance is given in Table 1.

\begin{tabular}{|c|c|c|c|}
\hline $\begin{array}{c}\text { Reduction in BMI in } \\
\mathbf{k g} / \mathbf{m} 2\end{array}$ & $\begin{array}{c}\text { Reduction in } \\
\text { Respiratory Rate/ mt }\end{array}$ & $\begin{array}{c}\text { Increase in } \\
\text { Expansion in } \mathbf{~ m}\end{array}$ & Increase in BHT/ min \\
\hline $0.598 \pm 0.091$ & $0.272 \pm 0.561$ & $1.4 \pm 0.239$ & $9.7 \pm 981$ \\
\hline $\mathrm{SD}=0.578$ & $\mathrm{SD}=3.55$ & $\mathrm{SD}=1.51$ & $\mathrm{SD}=6.2$ \\
\hline $\mathrm{t}=6.53$ & $\mathrm{t}=7.65$ & $\mathrm{t}=5.86$ & $\mathrm{t}=9.8$ \\
\hline $\mathrm{P}<.01 \mathrm{HS}$ & $\mathrm{P}<.01 \mathrm{HS}$ & $\mathrm{P}<.01 \mathrm{HS}$ & $\mathrm{P}<.01 \mathrm{HS}$ \\
\hline \multicolumn{2}{|c|}{ Table 1. Changes in BMI and Parameters related to Respiratory System in 40 Asthmatics } \\
\hline
\end{tabular}

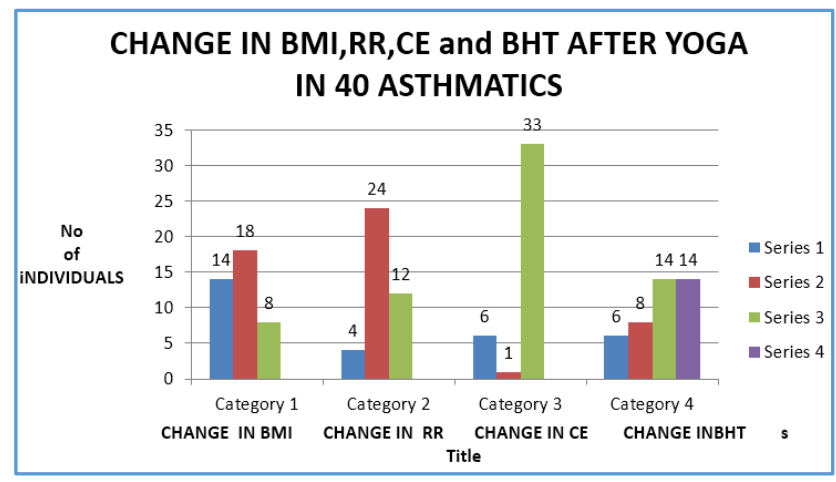

Figure 1. Changes in BMI and Parameters related to Respiratory System in 40 Asthmatics

The change in BMI in Category 1. It includes 3 groupsFirst with no change in BMI (consists of 14 patients), Second group with decrease in BMI less than $1 \mathrm{~kg} / \mathrm{m} 2$ (consists of 18 patients) and Third group with decrease in BMI more than 1 $\mathrm{kg} / \mathrm{m} 2$ (consists of 8 patients). The change in RR in Category 2.
It includes 3 groups- First group with no change in RR (consists of 4 patients), Second group with decrease in RR less than or equal to 5/ min (consists of 24 patients) and Third group with decrease in RR more than $5 /$ min (consists of 12 patients).

The change in chest expansion in Category 3. It includes 3 groups: First group with decrease in chest expansion (consists of 6 individuals), Second group with no change in chest expansion (consists of 1 individual) and Third group with increase in chest expansion less than or equal to 5 (consists of 33 individuals).

The change in BHT in category 4. It includes 4 groupsFirst with no change in BHT (consists of 6 patients), Second group with increase in BHT less than or equal to $5 \mathrm{sec}$ (consists of 8 patients), Third group with increase in BHT less than or equal to $10 \mathrm{sec}$ (consists of 14 patients) and Fourth group with increase in BHT more than $10 \mathrm{sec}$ (consists of 12 patients). 


\begin{tabular}{|c|c|c|c|c|c|c|c|}
\hline $\begin{array}{c}\text { Increase } \\
\text { in VC in } \mathbf{L}\end{array}$ & $\begin{array}{c}\text { Increase in } \\
\text { ERV in } \mathbf{L}\end{array}$ & $\begin{array}{c}\text { Increase } \\
\text { in IC in L }\end{array}$ & $\begin{array}{c}\text { Increase in } \\
\text { FVC in } \mathbf{~}\end{array}$ & $\begin{array}{c}\text { Increase in } \\
\text { FEV1 in } \mathbf{~}\end{array}$ & $\begin{array}{c}\text { Increase in } \\
\text { FEV1 } / \mathbf{F V C} \text { in } \mathbf{L}\end{array}$ & $\begin{array}{c}\text { Increase in PEFR } \\
\text { in } \mathbf{L} / \mathbf{m i n}\end{array}$ & $\begin{array}{c}\text { Increase in } \\
\mathbf{M V V} \text { in } \mathbf{L} / \mathbf{m i n}\end{array}$ \\
\hline $0.47 \pm 0.015$ & $0.328 \pm 096$ & $0.244 \pm 0.09$ & $0.204 \pm 0.094$ & $0.203 \pm .051$ & $2.04 \pm 1.83$ & $17.48 \pm 9.67$ & $13.2 \pm 2.69$ \\
\hline $\mathrm{SD}=.099$ & $\mathrm{SD}=0.611$ & $\mathrm{SD}=.566$ & $\mathrm{SD}=.597$ & $\mathrm{SD}=.322$ & $\mathrm{SD}=11.59$ & $\mathrm{SD}=61.14$ & $\mathrm{SD}=17$ \\
\hline $\mathrm{t}=9.45$ & $\mathrm{t}=3.39$ & $\mathrm{t}=2.72$ & $\mathrm{t}=2.16$ & $\mathrm{t}=3.98$ & $\mathrm{t}=1.112$ & $\mathrm{t}=1.34$ & $\mathrm{t}=4.9$ \\
\hline $\mathrm{P}<.01 \mathrm{HS}$ & $\mathrm{P}<.01 \mathrm{HS}$ & $\mathrm{P}<.01 \mathrm{HS}$ & $\mathrm{P}<.01 \mathrm{HS}$ & $\mathrm{p}<.01 \mathrm{HS}$ & $\mathrm{P}>.05 \mathrm{NS}$ & $\mathrm{P}>.05 \mathrm{NS}$ & $\mathrm{P}<.01 \mathrm{HS}$ \\
\hline \multicolumn{8}{|c|}{ Table 2. Change in PFT after Yoga in Asthmatics } \\
\hline
\end{tabular}

\begin{tabular}{|l|c|c|c|c|c|c|c|}
\hline & \multicolumn{7}{|c|}{ No. of Individuals in Different Groups } \\
\hline Change in Parameters in Litres & VC & ERV & IC & FVC & FEVI & MVV \\
\hline Group I & Decrease & 2 & 13 & 8 & 9 & 8 & 2 \\
\hline Group 2 & No change & 0 & 0 & 0 & 1 & 1 & 1 \\
\hline Group 3 & Increase upto 0.5 & 20 & 16 & 21 & 21 & 25 & 4 \\
\hline Group 4 & Increase 0.5 to 1 & 16 & 5 & 8 & 4 & 5 & 2 \\
\hline Group 5 & Increase more than 1 & 2 & 6 & 3 & 5 & 1 & 31 \\
\hline \multicolumn{7}{|c|}{ Table 3. Frequency of Individuals in Different Groups according to the Changes in Pulmonary } \\
Function Parameters after Yoga in Asthmatics \\
\hline
\end{tabular}

\begin{tabular}{|c|c|c|c|c|}
\hline Sl. No. & $\begin{array}{c}\text { Reduction } \\
\text { in } \mathrm{BMI} \text { in } \mathrm{kg} / \mathrm{m} 2\end{array}$ & $\begin{array}{c}\text { Reduction in } \\
\text { Respiratory Rate/mt }\end{array}$ & $\begin{array}{c}\text { Increase in } \\
\text { Expansion in } \mathrm{cm}\end{array}$ & $\begin{array}{c}\text { Increase in } \\
\mathrm{BHT} / \mathrm{min}\end{array}$ \\
\hline 1 & 1.4 & 14 & 1 & 10 \\
\hline 2 & 0.8 & 2 & 0 & 20 \\
\hline 3 & 0 & 2 & -1 & 15 \\
\hline 4 & 0.89 & 2 & 2 & 10 \\
\hline 5 & 0.82 & 6 & 3 & 25 \\
\hline 6 & 0 & 4 & 3 & 5 \\
\hline 7 & 0 & 0 & 1 & 20 \\
\hline 8 & 0 & 2 & 1 & 0 \\
\hline 9 & 1.7 & 4 & 3 & 25 \\
\hline 10 & 1 & 4 & -1 & 0 \\
\hline 11 & 0.8 & 8 & 1 & 5 \\
\hline 12 & 0.74 & 4 & 2 & 5 \\
\hline 13 & 0 & 9 & 1 & 10 \\
\hline 14 & 1.1 & 2 & 2 & 5 \\
\hline 15 & 0.4 & 2 & 2 & 5 \\
\hline 16 & 1.37 & 2 & -2 & 10 \\
\hline 17 & 0.8 & 4 & 2 & 10 \\
\hline 18 & 2.1 & 2 & 2 & 20 \\
\hline 19 & 0 & 2 & 1 & 10 \\
\hline 20 & 0.8 & 0 & 3 & 15 \\
\hline 21 & 0.9 & 0 & 3 & 0 \\
\hline 22 & 0 & 4 & 2 & 15 \\
\hline 23 & 1.6 & 4 & 3 & 10 \\
\hline 24 & 0 & 6 & 2 & 17 \\
\hline 25 & 0.35 & 4 & 4 & 10 \\
\hline 26 & 0.8 & 7 & -1 & 11 \\
\hline 27 & 0 & 6 & 1 & 13 \\
\hline 28 & 0.89 & 0 & 2 & 9 \\
\hline 29 & $\begin{array}{l}0.82 \\
\end{array}$ & 2 & 1 & 10 \\
\hline 30 & 0 & 4 & 2 & 8 \\
\hline 31 & 0 & 4 & 2 & 5 \\
\hline 32 & 1.4 & 8 & -2 & 10 \\
\hline 33 & 0.8 & 4 & 1 & 5 \\
\hline 34 & 0 & 9 & 2 & 5 \\
\hline 35 & 0.89 & 2 & 2 & 10 \\
\hline 36 & $\begin{array}{l}0.82 \\
\end{array}$ & 8 & -2 & 10 \\
\hline 37 & 0 & 4 & 2 & 20 \\
\hline
\end{tabular}




\begin{tabular}{|l|c|c|c|c|}
\hline 38 & 0 & 8 & 2 & 10 \\
\hline 39 & 0 & 4 & 1 & 15 \\
\hline 40 & 0.65 & 9 & $1.4 \pm 0.239$ & 0 \\
\hline & $0.598 \pm 0.091$ & $0.272 \pm 0.561$ & $\mathrm{SD}=1.51$ & $\mathrm{SD}=6.2$ \\
\hline & $\mathrm{SD}=0.578$ & $\mathrm{SD}=3.55$ & $\mathrm{t}=5.86$ & $\mathrm{t}=9.8$ \\
\hline & $\mathrm{t}=6.53$ & $\mathrm{t}=7.65$ & $\mathrm{P}<.01 \mathrm{HS}$ & $\mathrm{P}<.01 \mathrm{HS}$ \\
\hline & $\mathrm{P}<.01 \mathrm{HS}$ & $\mathrm{P}<.01 \mathrm{HS}$ & \\
\hline
\end{tabular}

\begin{tabular}{|c|c|c|c|c|c|c|c|c|}
\hline $\begin{array}{l}\text { Sl. } \\
\text { No. }\end{array}$ & $\begin{array}{l}\text { Increase } \\
\text { in VC in } L\end{array}$ & $\begin{array}{c}\text { Increase in } \\
\text { ERV in } L\end{array}$ & $\begin{array}{l}\text { Increase } \\
\text { in IC in } L\end{array}$ & $\begin{array}{c}\text { Increase in } \\
\text { FVC in } \mathrm{L}\end{array}$ & $\begin{array}{l}\text { Increase in } \\
\text { FEV1 in } L\end{array}$ & $\begin{array}{c}\text { Increase in } \\
\text { FEV1/FVC } \\
\text { in L }\end{array}$ & $\begin{array}{c}\text { Increase in } \\
\text { PEFR } \\
\text { in } \mathrm{L} / \mathrm{min} \\
\end{array}$ & $\begin{array}{c}\text { Increase in } \\
\text { MVV in } \\
\text { L/min }\end{array}$ \\
\hline 1 & .36 & .29 & .25 & .36 & .36 & 6.8 & .82 & 24.9 \\
\hline 2 & .55 & -.2 & .18 & 1.08 & .28 & -8.7 & .72 & 14.7 \\
\hline 3 & .76 & 1.48 & -.64 & .44 & .08 & 9.1 & .3 & 1.6 \\
\hline 4 & -.27 & 1.24 & -1.57 & -.76 & -.24 & 8.2 & 276 & 20.6 \\
\hline 5 & .15 & .2 & .15 & .08 & .4 & 11 & 1.01 & 2.4 \\
\hline 6 & .64 & .44 & .21 & -.67 & .38 & -30.8 & .93 & 3.7 \\
\hline 7 & .44 & -.52 & .98 & 1.12 & .76 & 9.3 & 1.17 & 24 \\
\hline 8 & .64 & .4 & .29 & .28 & .4 & 3.2 & 1.02 & 6.4 \\
\hline 9 & .88 & .16 & .44 & .36 & .2 & -4.6 & .87 & 11.2 \\
\hline 10 & .67 & -.61 & .79 & -.28 & -.2 & -12.6 & .12 & -18.9 \\
\hline 11 & .24 & -.3 & -.13 & -1.16 & -.72 & -51.1 & 1.7 & 77.3 \\
\hline 12 & .22 & .09 & 1.12 & .6 & .01 & 2.8 & 1.23 & 10 \\
\hline 13 & .33 & .76 & .77 & 1.08 & .2 & 1.7 & .6 & .5 \\
\hline 14 & .47 & .46 & 1.19 & 0.05 & .25 & .9 & 2.1 & 12 \\
\hline 15 & .44 & -.87 & 1.32 & .2 & .56 & 5.2 & 1.75 & 19.8 \\
\hline 16 & .78 & 1.15 & .48 & .76 & .68 & 7.7 & .25 & 23.7 \\
\hline 17 & 1.07 & -0.19 & .05 & .95 & .02 & 1.6 & 1.02 & 12.7 \\
\hline 19 & .67 & .1 & .1 & .45 & .11 & 3 &, 4 & 1 \\
\hline 20 & .85 & .35 & .21 & 0 & .2 & $4-8$ & 1 & 9.6 \\
\hline 21 & .29 & .06 & .06 & -0.1 & .06 & 8.8 &, 23 & 4 \\
\hline 22 & .03 & .12 & .11 & 0.05 & -.14 & 6 & -0.02 & 0 \\
\hline 23 & .15 & -0.04 & -.2 & 0.33 & .1 & 9.6 & 1.06 & 36 \\
\hline 24 & .15 & 1.11 & .86 & 0.11 & .04 & 1.8 & 1 & 21 \\
\hline 25 & .6 & .26 & .24 & .48 & 0 & 1.4 & 1.38 & 12.7 \\
\hline 27 & .55 & -.3 & .18 & 1.12 & .2 & .9 & .72 & 3.7 \\
\hline 26 & .36 & -.61 & .25 & -.67 & .4 & 1.7 & .82 & 2.4 \\
\hline 28 & .76 & .09 & -.64 & .28 & -.2 & 5.2 & .3 & 24 \\
\hline 29 & -.27 & .76 & -1.57 & .36 & -.72 & 7.7 & 276 & 6.4 \\
\hline 30 & .15 & .46 & .15 & -.28 & .01 & 1.6 & 1.01 & 11.2 \\
\hline 31 & .64 & -.87 & .21 & -1.16 & .2 & 15.7 & .93 & -18.9 \\
\hline 32 & .44 & 1.15 & .98 & .06 & -.2 & 3 & 1.17 & 77.3 \\
\hline 33 & .67 & -0.19 & .29 & 0.05 & -.72 & $4-8$ & 1.02 & 10 \\
\hline 34 & .24 & .62 & .44 & 0.33 & .01 & 8.8 & .87 & .5 \\
\hline 35 & .22 & -.3 & .79 & 0.11 & .2 & 6 & .4 & 12 \\
\hline 36 & .33 & .09 & -.13 & .48 & .25 & 9.6 & 1 & 19.8 \\
\hline 37 & .47 & .76 & 1.12 & -.67 & .56 & 1.8 & .23 & 23.7 \\
\hline 38 & .44 & .46 & .77 & 1.12 & .68 & 1.4 & -0.02 & 12.7 \\
\hline 39 & .78 & -.87 & .44 & .28 & .2 & 1.7 & 1,06 & 24 \\
\hline 40 & 1.07 & 1.15 & .21 & .36 & .01 & .9 & 1 & 1 \\
\hline & $0.47 \pm 0.015$ & $0.328 \pm 096$ & $0.244 \pm 0.09$ & $0.204 \pm 0.094$ & $0.203 \pm .051$ & $2.04 \pm 1.83$ & $17.48 \pm 9.67$ & $13.2 \pm 2.69$ \\
\hline & $\mathrm{SD}=.099$ & $\mathrm{SD}=0.611$ & $\mathrm{SD}=.566$ & $\mathrm{SD}=.597$ & $\mathrm{SD}=.322$ & $\mathrm{SD}=11.59$ & $\mathrm{SD}=61.14$ & $\mathrm{SD}=17$ \\
\hline & $\mathrm{t}=9.45$ & $\mathrm{t}=3.39$ & $t=2.72$ & $\mathrm{t}=2.16$ & $\mathrm{t}=3.98$ & $\mathrm{t}=1.112$ & $\mathrm{t}=1.34$ & $\mathrm{t}=4.9$ \\
\hline & $\mathrm{P}<.01 \mathrm{HS}$ & $\mathrm{P}<.01 \mathrm{HS}$ & $\mathrm{P}<.01 \mathrm{HS}$ & $\mathrm{P}<.01 \mathrm{HS}$ & $\mathrm{p}<.01 \mathrm{HS}$ & $\mathrm{P}>.05 \mathrm{NS}$ & $\mathrm{P}>.05 \mathrm{NS}$ & $\mathrm{P}<.01 \mathrm{HS}$ \\
\hline \multicolumn{9}{|c|}{ Table 5. Change in PFT after Yoga in Asthmatics } \\
\hline
\end{tabular}




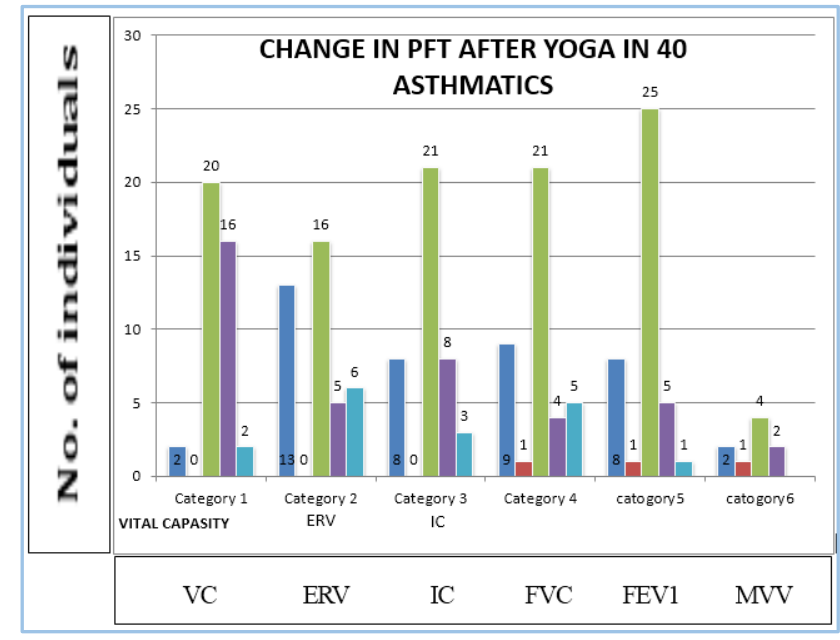

Figure 2. Change in PFT after Yoga in 40 Asthmatics

Each category consists of 5 series of bar diagrams, which represent 5 groups. 1st Group with Decrease, 2nd Group with No change, 3rd Group with Increase up to 0.1, 4th Group with increase of 0.5 to 1 and the 5th Group with increase more than 1.

\section{DISCUSSION}

The parameters like respiratory rate and body mass index showed a significant reduction after Yoga practice. Yoga resulted in significant increase in chest expansion and breath holding time in asthmatics following Yoga practice. All the pulmonary function parameters namely Vital capacity, Expiratory reserve volume, Inspiratory capacity, Forced vital capacity, Forced expiratory volume in 1 second and Maximum voluntary ventilation showed a significant increase after Yoga practice in asthmatics. But the increase in Peak expiratory flow rate was not significant. The subjective decrease in frequency and severity of symptoms was observed in most of the asthmatics following yoga. This suggests the effectiveness of yoga as a possible control measure for bronchial asthma. The increase in breath holding time and chest expansion can be attributed to the relaxation of skeletal muscle achieved due to yoga. It led to improvement of subjective well-being also. The Bronchodilation produced by correct breathing pattern, widening of respiratory bronchioles and perfusion of large number of alveoli can be regarded as the cause for improvements. The decreased airway resistance caused by relaxation of somatic musculature due to yoga and meditation is another possible contributory factor. Further deep and controlled breathing desensitises the sensory nerve ending helping to reduce the response of the bronchus to the environmental allergens.[2]

Makarasana, Suryanamaskara, Ushtrasana, Dhanurasana and Matsyasana are very useful for patients with asthma and bronchitis. During Makarasana, chest is expanded allowing an increased amount of air to enter the lungs. Similarly, Suryanamaskara accentuates the exchange of air to and from lungs, opens up and expand alveoli and exercises the muscles of the chest wall. Ushtrasana expands the rib cage and the associated muscles are made more supple facilitating deeper breathing. Dhanurasana realigns the back and improves breathing. During Matsyasana, the rib cage and lungs are given an accentuated stretch which helps to improve breathing. [3] Kapalabhati cleans out the lungs, improves the elasticity of lungs and favours more efficient gas exchange in patients with COPD. Kapalabhati practiced in asymptomatic intervals may be useful also in making respiratory muscles stronger as well as improving the general tone of the lungs. Moreover the reduction in psychological hyperreactivity and emotional instability achieved by Yoga can reduce efferent vagal reactivity.[4],[1],[5],[6] Yoga exercise have also been reported to increase endogenous corticosteroid release.[1] Goyeche et al suggests the presence of psychosomatic imbalance in most of the asthmatics. Yoga therapy relaxes mind and body along with reducing the emotional disturbances and thereby modifying the airway resistance. ${ }^{[7]}$ Increase in vagal tone and efferent vagal discharge and bronchoconstriction produced secondary to emotional stress is known as a definite precipitating factor in asthma. [8]

\section{CONCLUSION}

Yoga can be useful in the field of medicine by its influence on body and mind. It also results in a more relaxed mental state and is beneficial in the treatment of psychosomatic disorders. The reduction in respiratory rate and body mass index after 1 hour yoga practice for 40 days regularly in asthma patients throws light into the usefulness of yoga in the treatment of bronchial asthma. The present study also shows a significant increase in breath holding time and chest expansion. There was significant improvement in pulmonary function tests namely VC, ERV, IC, FVC, FEV1 and MVV after the practice of yoga. But the increase in PEFR was not significant.

\section{ACKNOWLEDGEMENTS}

I am extremely thankful to Yogacharya N Vijayaraghavan and his fellowmen Sathyananda Yoga Research Centre, Calicut and the host of the people who were subjects of this study. My sincere thanks to Dr. Anoopa Lucose, Dept. of Community Medicine for her expert opinions which was helpful for the preparation of the paper.

\author{
Abbreviations \\ COPD- Chronic Obstructive Pulmonary Disease. \\ PFT- Pulmonary Function Tests. \\ VC- Vital Capacity. \\ ERV- Expiratory Reserve Volume. \\ IC- Inspiratory Capacity. \\ FVC- Forced Vital CAPACITY. \\ FEVI/FVC- Forced Expiratory Volume in $1 \mathrm{sec} /$ Forced Vital \\ Capacity. \\ PEFR- Peak Expiratory Flow Rate. \\ MVV- Maximum Voluntary Ventilation. \\ MEFV- Maximum Expiratory Flow Volume Curve. \\ RV- Residual Volume.
}

\section{REFERENCES}

[1] Singh V, Wisniewski A, Britton J, et al. Effect of yoga breathing exercises (pranayama) on airway reactivity in subjects with asthma. Lancet 1990;335(8702):1381-3.

[2] Khanam AA, Sachdeva U, Guleria R, et al. Study of pulmonary and autonomic functions of asthma patients after yoga training. Indian J Physiol Pharmacol 1996;40(4):318-24. 


\section{Jemds.com}

[3] Saraswati SS. A systematic course in ancient tantric techniques of Yoga and Kriya. Yoga publications Trust. Munger Bihar. India.

[4] Nagarathna R, Nagendra HR. Yoga for bronchial asthma: a controlled study. Br Med J (Clin Res Ed) 1985;291(6502):1077-9.

[5] Grippi MA, Elias JA, Fishman JA, et al. Fishman's pulmonary diseases and disorders. Chapter 36, Pulmonary function Testing. McGraw-Hill Global Education 535-40, 544-8.

\section{Original Research Article}

[6] Seaton AA, Leitch G, Seaton D. Crofton and Doughla's. Respiratory diseases. $5^{\text {th }}$ edn. Vol 2. Wiley 2008:1696.

[7] Sathyaprabha TN, Murthy H, Murthy BT. Efficacy of naturopathy and yoga in bronchial asthma-a self controlled matched study. Indian J Physiol Pharmacol 2001;45(1):80-6.

[8] Weinberger SE, Barbara A. Principles of pulmonary medicine Asthma. Cockril and Jess Mandel on science pp 72-85. Direct.com. 